\title{
Electrochemical and Thermal Stability of Nystatin Drug
}

\author{
SIMONA IORDACHE, BOGDAN TUTUNARU*, ADRIANA SAMIDE, ALEXANDRU POPESCU \\ University of Craiova, Faculty of Sciences, Department of Chemistry, 107i Calea Bucuresti, 200478, Craiova, Romania
}

\begin{abstract}
The analysis of synthetic / residual drugs is very important due to their systemic toxicity. Simple and rapid electrochemical degradation of nystatin drug was accomplished using constant current density electrolysis on platinum electrode. Electrochemical behavior of nystatin drug was investigated on different metallic electrodes by cyclic voltammetry. In saline solution, distinctive oxidation peak are observed on the lead and copper electrodes. The degree of electrochemical degradation reaches the maximum value of $100 \%$ in 10 minutes on platinum electrodes. Thermal stability of nystatin drug was studied by simultaneous TG / DSC analysis. The thermogravimetric and heat flow curves indicated a relatively high stability up to $150{ }^{\circ} \mathrm{C}$.
\end{abstract}

Keywords: nystatin, electrochemistry, spectrophotometry, thermochemistry

Nystatin is a tetraene antifugal antibiotic (fig. 1) used for the treatment of candidiasis of skin and membranes [1] being administrated either as suspension or gel forms. Nystatin powder must be stored in containers at low temperatures $\left(<10^{\circ} \mathrm{C}\right)$ and protected from light, heat and air.

Stability testing provide useful information on the stability of pharmaceutical subtances, storage conditions and selflives because their degradation can result in a decreased efficacy.

Most of the analytical methods used to study the determination of nystatin are based on electrochemical electrodes [2]; spectrophotometry [3]; densitometry [4]; micellar electrokinetic capillary chromatography [5] and liquid chromatography [6]. Recent research works have been evaluate the effect of nystatin nanoparticles on the physicochemical and antifugal properties [7]; migraine [8] or to improve the oral antifugal properties [9]. More efficient mucoadhesive oral films and alginate microsphere as nystatin carieers were developed by emulsification / internal gelation method [10,11]. Nystatin antifugal activity presents higher efficacy when nystatin is combined with other compounds [12-16].

Forced degradation of drugs under different factors (temperature, UV-light, acid/base hydrolysis) have the main objective to evaluate the storage conditions and also the optimal conditions to degrade them from wastewaters [ 1 , $17,18]$.

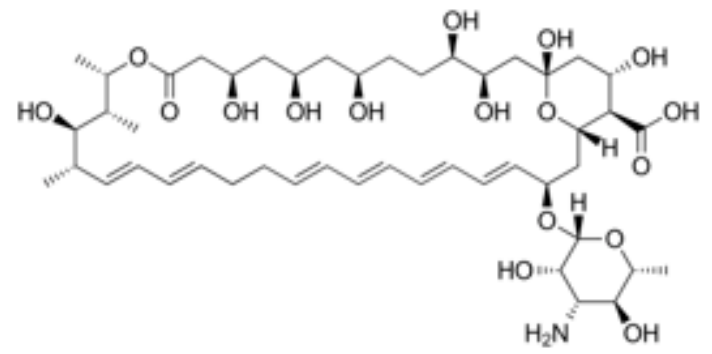

Fig. 1. Chemical structure of nystatin

The objective of this study was to establish the optimal electrocatalytic activity of different metallic anodes over the electrochemical degradation of nystatin and also to evaluate its thermal stability.

\section{Experimental part}

Nystatin as yellow powder was purchased from a local pharmacy and presented pharmaceutical grade purity. Natrium chloride (Sigma-Aldrich) was of reagent grade
(>99.8\%). Copper ( $\mathrm{Cu})$, nickel ( $\mathrm{Ni})$, lead (Pb) and platinum (Pt) plates electrodes with an effective surface of $2 \mathrm{~cm}^{2}$.

Cyclic voltammograms of aqueous solution of nystatin drug in the presence of chloride ions were performed using a VoltaLab 40 and a three electrode one compartment electrochemical cell. Both anode and cathode were identical and represented by different metallic plates. A silver chloride electrode was used as reference electrode. VoltaMaster 4 software was used for control and experimental data processing. Cyclic voltammograms were recorded with a potential sweep rate of $100 \mathrm{mV} \cdot \mathrm{s}^{-1}$.

UV-Vis spectrophotometry of aqueous solution of $10^{-1}$ $\mathrm{mol} \cdot \mathrm{L}^{-1} \mathrm{NaCl}$ solution containing $5 \cdot 10^{-5} \mathrm{~mol} \cdot \mathrm{L}^{-1}$ nystatin, electrolized on differentmetallic electrodes was performed using a Varian Cary UV-Vis spectrophotometer. The electrochemical degradation was performed at a constant current density of $15 \mathrm{~mA} \cdot \mathrm{cm}^{-2}$.

Thermal analysis of nystatin drug was performed in the temperature range varying from 25 to $500^{\circ} \mathrm{C}$. Thermal behaviour was studied in this temperature range with a heating rate of $10^{\circ} \mathrm{C} \cdot \mathrm{min}^{-1}$ in an aluminium crucible using a Perkin Elmer thermal analyser (Pyris software) in an inert $\mathrm{N}_{2}$ atmosphere. The nitrogen gas was purged at a constant flow of $150 \mathrm{~mL} \cdot \mathrm{min}^{-1}$.

\section{Results and discussions}

Electrochemical behavior of nystatin drug on metallic electrodes

The electrochemical degradation processes of the organic compounds are strongly influenced by the nature of the electrode used, thus was studied the electrochemical degradation of Nystatin (Nyst) $5 \cdot 10^{-5} \mathrm{~mol} \cdot \mathrm{L}^{-1}, \mathrm{NaCl}$ $10^{-1} \mathrm{~mol}^{-1} \mathrm{~L}^{-1}$ on different metallic electrodes: $\mathrm{Cu}, \mathrm{Ni}, \mathrm{Pb}$ and Pt.

In order to elucidate the electrochemical degradation mechanisms, the cyclic voltamograms (fig. 2) of these electrodes were recorded in $10^{-1} \mathrm{~mol} \cdot \mathrm{L}^{-1} \mathrm{NaCl}$ solution both in the absence of (black) and in the presence of (red) 5:10${ }^{5} \mathrm{~mol} \cdot \mathrm{L}^{-1}$ nystatin with a sweeping rate of $100 \mathrm{mV} \cdot \mathrm{s}^{-1}$.

In the case of the $\mathrm{Pb}$ electrode, the presence of nystatin molecules in the electrolyte solution predominantly influences the anode processes (fig. 2). During anodic polarization, the maximum current density recorded at a potential of $+0.1 \mathrm{~V}$ attributed to lead oxidation / superficial oxide formation is displaced to $-0.1 \mathrm{~V}$. The decrease of anodic current densities values from $70 \mathrm{~mA} \cdot \mathrm{cm}^{-2}$ at 30 $\mathrm{mA} \cdot \mathrm{cm}^{-2}$ indicates a strong adsorption process of the nystatin molecules at the metal surface. At potential values

*email: tutunaruchim@yahoo.com 
greater than $0.6 \mathrm{~V}$, current densities have higher values in the presence of nystatin molecules which means that in the activity zone the nystatin molecules favor lead dissolution.

The cyclic voltamogram of the Ni electrode shows an increase in current densities in the presence of nystatin only in the activity area (potential range $0 \div 1 \mathrm{~V}$ ). In the presence of nystatin no significant changes in the cyclic voltammogram can be observed at the current density used for the electrochemical degradation of this biologically active compound.

Cyclic voltammograms of the copper electrode in the $0.1 \mathrm{M} \mathrm{NaCl}$ solution both in the absence and presence of $5 \cdot 10^{-5} \mathrm{~mol} \cdot \mathrm{L}^{-1}$ Nyst indicate high values of current densities. As can be seen from figure 2, in the presence of nystatin molecules, there is a change in both anodic and cathodic processes. The maximum current density recorded at the potential value of $\sim 0.6 \mathrm{~V}$ corresponds to the oxidation of nystatin. Anodic current density values are clearly superior in the presence of drug molecules starting at low potential potentials of $\sim 0.2 \mathrm{~V}$. This phenomenon indicates a strong adsorption of organic molecules on the surface of the copper electrode. The appearance of a new peak of cathodic current densities (-0.7 V) indicates the presence of a species reduction process; these being most likely represented by complexes of nystatin with copper ions.
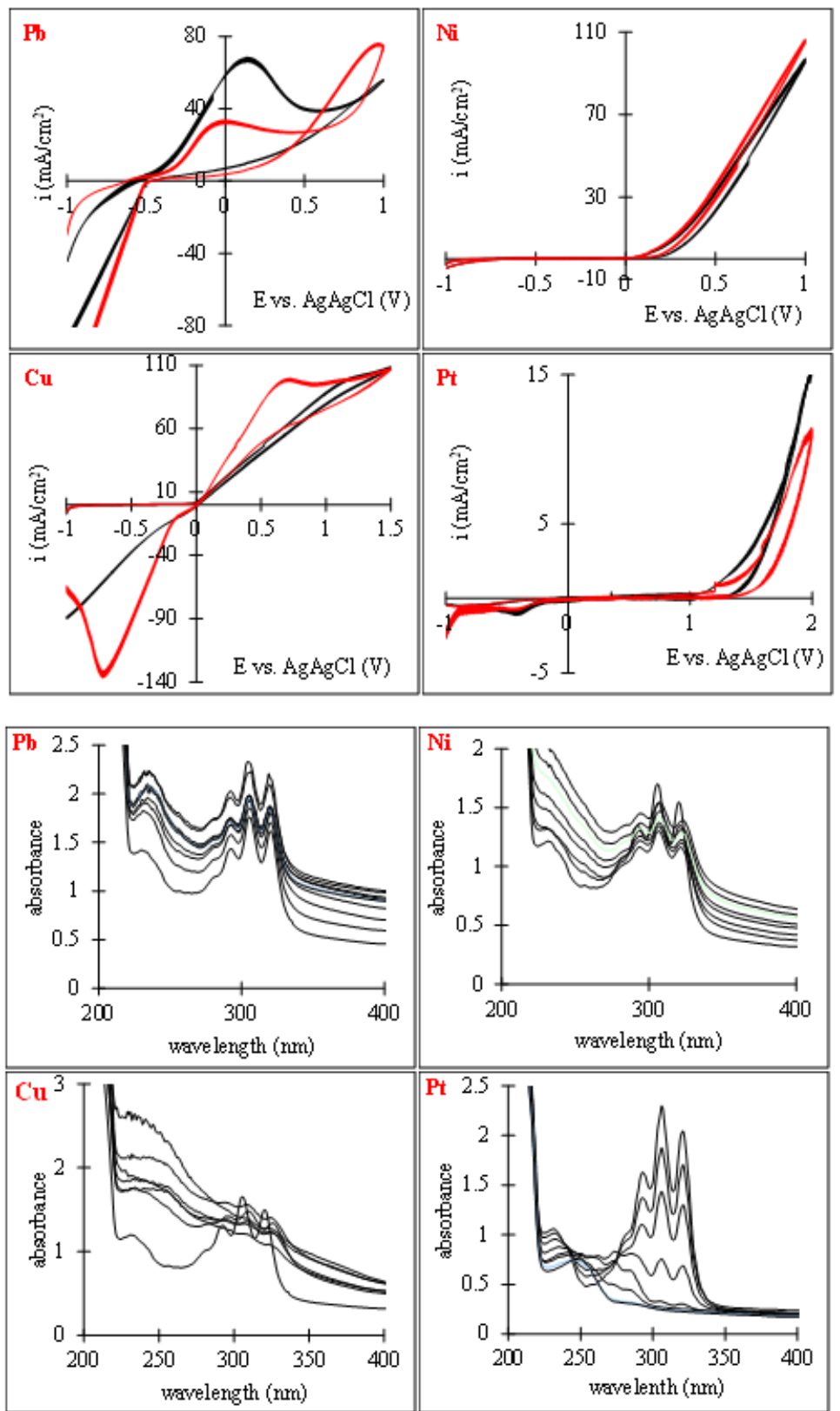

504

http://www.revistadechimie.ro
The cyclic voltamograms of the Pt electrode in the $10^{-1}$ $\mathrm{mol} \cdot \mathrm{L}^{-1} \mathrm{NaCl}$ solution, in the absence and in the presence of $5 \cdot 10^{-5} \mathrm{~mol} \cdot \mathrm{L}^{-1}$ nystatin molecules, are characteristic of an inert electrode. The difference between the two voltamograms is given by a higher hysteresis cycle in the presence of nystatin due to the intensification of the electrode processes.

The UV-Vis spectra of nystatin solution were recorded from 3 to $3 \mathrm{~min}$, over a period of $20 \mathrm{~min}$, during the electrolysis process at constant current density.

Similar to the electrochemical behavior of the nickel electrode (fig. 3), and in this case there is a strong interaction between the lead ions and the nystatin molecules without excluding the possibility of formation of complexes. The degree of degradation, in this case, also has an inflection point corresponding to 50\% achieved at $10 \mathrm{~min}$ after the start of the electrolysis (fig. 4).

From figure 3, it can be observed the shift of the base line to higher absorbance values with increasing electrolysis time, indicating a change in the composition of the electrolyte solution in the case of nickel electrode. UV-Vis spectra moves to higher absorbance values; the absorption maxima characteristic of nystatin decreases in intensity until the end of electrolysis. The degree of degradation has an inflection point corresponding to $\sim 60 \%$ achieved at 5

Fig. 2. Cyclic voltamograms of $\mathrm{Pb}, \mathrm{Ni}, \mathrm{Cu}$ and Pt electrodes in $10^{-1} \mathrm{~mol} \cdot \mathrm{L}^{-1} \mathrm{NaCl}$ solution both in the absence of (black) and in the presence of (red) $5 \cdot 10^{-5} \mathrm{~mol} \cdot \mathrm{L}^{-1}$ nystatin, sweeping rate of $100 \mathrm{mV} \cdot \mathrm{s}^{-1}$

Fig. 3. UV-Vis spectra of $5 \cdot 10^{-5} \mathrm{~mol} \cdot \mathrm{L}^{-1} \mathrm{Nyst}, 10^{-1} \mathrm{~mol} \cdot \mathrm{L}^{-1} \mathrm{NaCl}$ solution electrolyzed on $\mathrm{Pb}, \mathrm{Ni}, \mathrm{Cu}$ and $\mathrm{Pt}$ electrodes 
min, after which a further $10 \%$ increase is recorded until the end of the electrolysis (fig. 4).

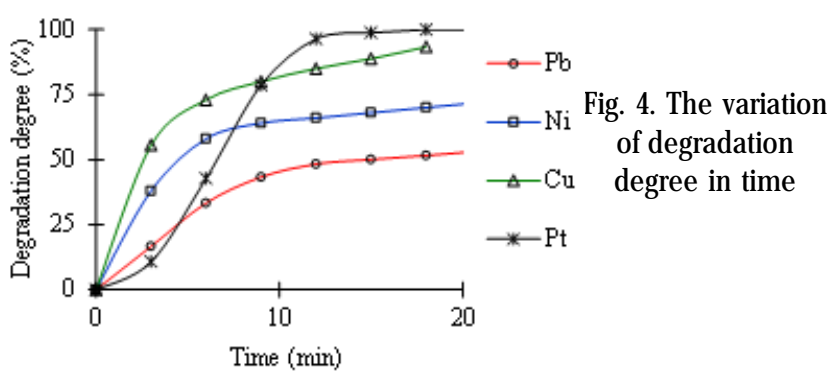

UV-Vis spectra indicate a strong interaction of copper ions with organic molecules (fig.3). Since the firstmoments of electrolysis, the degradation of nystatin is higher, reaching a $50 \%$ degradation degree in just a few minutes. At the end of the electrolysis, after $20 \mathrm{~min}$, the degree of degradation reaches almost $100 \%$.

Spectrophotograms of the electrolyzed solution show the decrease in the intensities of all three nystatin-specific absorption maxima. Among the studied electrode materials, platinum electrode exhibits superior electrocatalytic activity for both the degradation of nystatin molecules and the electrochemical generation of the active chloride species. Consequently, the degree of degradation reaches the maximum value (100 \%) in the shortest time $(\sim 10 \mathrm{~min})$.

\section{Thermal behavior of nystatin drug}

Thermal degradation of nystatin was performed in an inert atmosphere. The nitrogen gas was purged in the furnace at a constant flow of $150 \mathrm{~mL} \cdot \mathrm{min}^{-1}$. A nystatin sample having a mass between 3 and $5 \mathrm{mg}$ was weighed into an aluminum crucible and heated from ambient temperature to $500^{\circ} \mathrm{C}$ with a heating rate of $10^{\circ} \mathrm{C} \cdot \mathrm{min}^{-1}$.

In figure 5 the thermogravimetric curve of nystatin as the percentage change of mass in relation to temperature (TG curve) and the first order derivative of this curve (dTG curve) is presented.

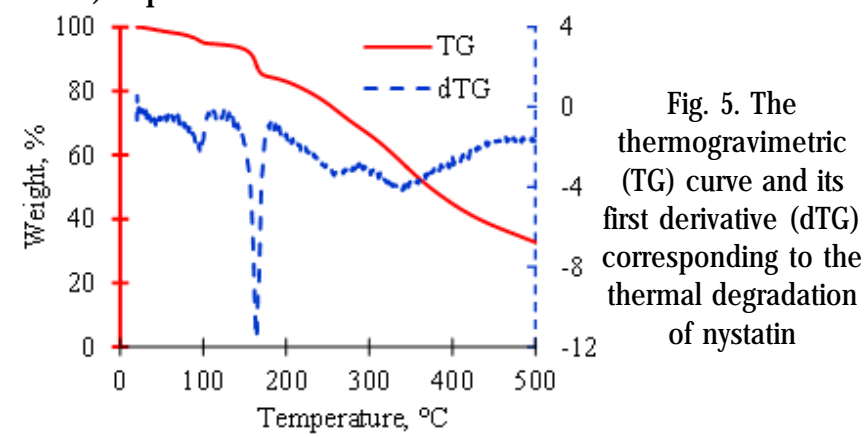

In figure 6 the variation of the heat flow is presented (DSC curve) in the analyzed temperature range as well as the first order derivative of this curve (dDSC curve).

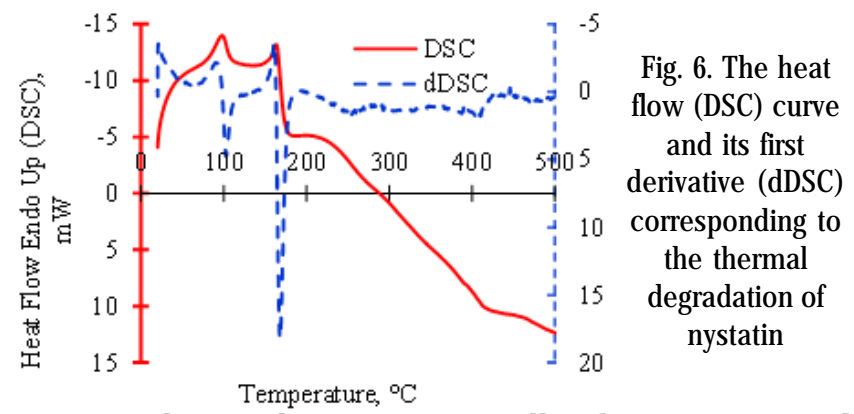

By analyzing the experimentally observations and presented in figures 5 and 6 it can be stated:

- at a temperature of about $90^{\circ} \mathrm{C}$ the sample mass decreases by an average of $5 \%$ (TG curve). This decrease is due to the evaporation of slightly volatile impurities and / or moisture. This phenomenon is an endothermic process by associating its corresponding peak in the DSC / dDSC curves;

- the second endothermic process (DSC curve) corresponding to a 12 percent decrease in mass (TG curve) is recorded in the temperature range from 150 to $170^{\circ} \mathrm{C}$. This process corresponds to a partial degradation of nystatin molecules;

- tt temperatures above $170^{\circ} \mathrm{C}$, the mass gradually decreases due to a deeper structural degradation of nystatin. Atthe end of the experiment $\left(500^{\circ} \mathrm{C}\right)$, the crucible remains $\sim 30 \%$ unburnt yet to a total combustion.

\section{Conclusions}

The study of electrochemical behavior was performed using cyclic voltammetry and electrolysis at constant current density.

Experimental observations have led to the conclusion that nystatin molecules are electrochemically degraded on different metallic electrodes, $\mathrm{Cu}, \mathrm{Ni}, \mathrm{Pb}, \mathrm{Pt}$. Determination of degrees of degradation was performed by spectrophotometric UV-Vis analysis of electrolyzed solutions. Determinations have shown that values of degrees of degradation vary in the order of: $\mathrm{Pb}<\mathrm{Ni}<\mathrm{Cu}$ $<$ Pt having values of $55<73<93<100$.

Thermal analysis indicated a degradation of nystatin starting at a temperature of about $160{ }^{\circ} \mathrm{C}$. At the end of the thermal analysis, a residue of $\sim 30 \%$ from the initial mass was obtained.

\section{References}

1. CIONE, A.P., LIBERALE, M.J. SILVA, P.M., Braz. J. Pharm. Sci., 46, no. 2, 2010, p. 305.

2. MASCINI, M., MEMOLI, A., OLANA, F., Anal. Chim. Acta, 200, 1987, p. 237.

3. BOTSOGLOU, N.A., FLETOURIS, D.J ., J. Agric. Food Chem., 44, no. 5, 1996, p. 1271.

4. INJAC, R., STRUKELJ , B., DJ ORDJ VIC-MILIC, V., KARLJ IKOVIC-RAJ IC, K., LINGEMAN, H., J. Sci. Food Agriculture, 88, no. 9, 2008, p. 1576.

5. INJ AC, R., KAC, J., MLINARIC, A., KARLJ IKOVIC-RAJIC, K., J. Sep. Sci., 29, no. 9, 2006, p. 1288.

6. GALLEGO, J.M.L., ARROYO, J.P., Chromatographia, 55, no. 11-12, 2002, p. 749.

7. MOHAMMADI, G., NAMADI, E., MIKAEILI, A., MOHAMMADI, P., ADIBKIA, K., J. Drug Deliv. Sci. Tech., 38, 2017, p. 90.

8. GIROTRA, P., THAKUR, A., KUMAR, A., SINGH, S.K., Int. J. Biol. Macromol., 96, 2017, p. 687.

9. KASSEM, A.A., MOHSEN, A.M., AHMED, R.S., ESSAM, T.M., J. Molec. Liq., 218, no. 6, 2016, p. 219

10. GAJDOSOVA, M., VETCHY, D., DOLEZEL, P., GAJDZIOK, J., LANDOVA, H., MUSELIK, J., ZEMANA, J., KNOTEK, Z., HAUPTMAN, K., JEKL, V., J. Appl. Biomed., 14, no. 4, 2016, p. 247.

11. MARTIN, M.J., CALPENA, A.C., FERNANDEZ, F., MALLANDRICH, M., GALVEZ, P., CLARES, B., Carbohydr. Polym., 117, no. 3, 2015, p. 140.

12. CHULKOV, E.G. SCHAGINA, L.V., OSTROUMOVA, O.S., Biochim. Biophys. Acta (BBA) - Biomembranes, 1848, no. 1, part A, 2015, p. 192.

13. BADEA, G., BORS, A.G., LACATUSU, I., OPREA, O., UNGUREANU, C., STAN, R., MEGHEA, A., C.,Rev. Chim. (Bucharest), 2015, p. 668. 14. SEMIS, R., NAHMIAS, M., LEV, S., FRENKEL, M., SEGAL, E., J. Med. Mycology, 25, no. 1, (2015) 63.

15. MANSOURIAN, A., BOOJ ARPOUR, N., ASHNAGAR, S., BEITOLLAHI, J.M., SHAMSHIRI, A.R., J. Med. Mycology, 24, no. 4, 2014, el63.

16. REN, J ., CUI, Y., ZHANG, F., CUI, H., NI, X., CHEN, F., LI, L., XIA, H., Microbiol. Res., 169, no. 7-8, 2014, p. 602.

17. MOBASHERI, M., ATTAR, H., SORKHABADI, S.M.R., KHAMESIPOUR, A., JAAFARI, M.R., Molecules, 21, no. 1, 2016, p. 6.

18. HEMMATEENEJ AD, B., NEKOEINIA, M., ABSALAN, G., ANSARI, M., Journal of AOAC International, 97, no. 4, 2014, 1206.

Manuscript received: 10.05 .2018 